
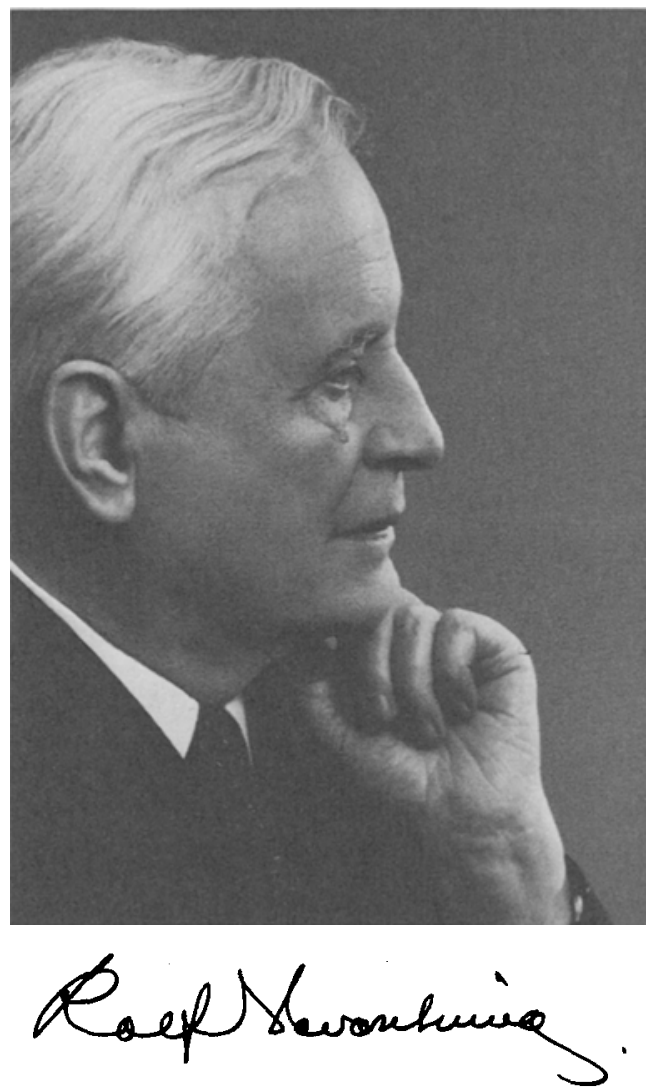

\title{
Rolf Nevanlinna in memoriam
}

Rolf Herman Nevanlinna was born in Joensuu, Finland, October 22, 1895 and died in Helsinki on May 29, 1980. He came from a prominent family many members of which, male and female, had shown distinct talent for mathematics even when not professional mathematicians. His father, Otto Nevanlinna, was the leading teacher of mathematics at the gymnasium level. An uncle, E. R. Neovius, was professor of mathematics at the University of Helsinki and known for notable contributions to the Calculus of Variation. His brother, Frithiof Nevanlinna, was also, in later years, professor at the same university; he is best known for joint work with the slightly younger Rolf. The two brothers were very close and inspired each other in and outside of mathematics.

1-822906 Acta Mathematica 149 
Rolf Nevanlinna studied at the University of Helsinki, mainly under the guidance of Ernst Lindelöf, himself a mathematician of world renown. When Nevanlinnna entered the university Lindelöf was no longer active in research, but had devoted himself exclusively to the teaching of his many students of which Rolf Nevanlinna was to become the most famous. Nevanlinna defended his thesis 1919 , became a docent 1922, and was appointed full professor 1926.

Much later, in 1946, he accepted a call to the University of Zürich, where, paradoxically, he became the successor of a student of his, the writer of these lines. In 1948 he was made a member of the Academy of Finland, an honor shared by twelve of the most prominent representatives of art and science in the country. As academician he had to relinquish his regular professorship in Zürich, but he continued as an honorary professor until his retirement, in 1963, when he returned to Finland.

In the course of his life Nevanlinna received many honorary degrees, including Heidelberg, Giessen, Freie Universität Berlin, Glasgow, Bukarest, Istanbul. He was a member of, among others, the following learned societies: Academia Scientiarum Fennica, Societas Scientiarum Fennica, Gesellschaft der Wissenschaften zu Göttingen, Preussische Akademie der Wissenschaften, Kungliga Svenska Vetenskapsakademien, Kongelige Danske Videnskabernes Selskab, Deutsche Akademie der Naturforscher Leopoldina. He was awarded the Wihuri International Prize 1958.

Nevanlinna's fame came early. It was triggered mainly by his early work on meromorphic functions which was summarized in his Acta Mathematica paper of 1925 . The theory of entire and meromorphic functions had been almost exclusively in the hands of the French school headed by Picard, Borel and Hadamard. For meromorphic functions the only efficient tool was the Weierstrass product representation; for entire functions there was also the power series development. Nevanlinna introduced a radical innovation by using methods of potential theory for the study of the harmonic function $\log |f(z)|$ with logarithmic poles at the zeros and poles of the meromorphic function $f(z)$. The main contact was Jensen's formula which he rewrote in the now familiar form

$$
N(r, \infty)+1 / 2 \pi \int_{0}^{2 \pi}+\stackrel{+}{\log }|f| d \theta=N(r, 0)+1 / 2 \pi \int_{0}^{2 \pi}+\stackrel{+}{\log 1 /|f|}|d \theta+\log | f(0) \mid
$$

of the First Main Theorem. It has been said that this step marks the birth of what was to become and still is called Nevanlinna theory in all its facets and variations. Nevanlin- 
na's first version of the Second Main Theorem dealt with the distribution of three values, and it was observed by Collingwood and Littlewood that the theorem and its proof carry over to the more general situation of any $q$ values, thereby leading to the Defect Relation. Collingwood's and Littlewood's merit should not be underrated, but it was Nevanlinna who found the key that opened the gate.

It will probably never be fully clear to what extent Frithiof Nevanlinna took part in the initial work on meromorphic functions. It is evident, however, that many of the ideas that made Nevanlinna theory possible were present already in the joint paper F. and R. Nevanlinna, "Über die Eigenschaften analytischer Funktionen in der Umgebung einer singulären Stelle oder Linie". This is a truly remarkable paper, and to read it is sheer delight. To my knowledge the Gauss-Green-Stokes theorem had never before been put to so efficient use in the framework of complex analytic functions. Ultimately, this paper led to Rolf Nevanlinna's lifelong involvement with harmonic measures. Even though it had already been used (T. Carleman, A. Ostrowski) there is no doubt that the brothers Nevanlinna had a major share in making it the valuable instrument it became. Rolf Nevanlinna's famous monograph "Eindeutige analytische Funktionen" is to a great extent a treatise on harmonic measures. Later work of Nevanlinna included contributions to Riemann surfaces, relativity, differential geometry, and foundations of geometry.

Besides being a leading mathematician Nevanlinna was also an administrator of great skill. He was rector of the University of Helsinki during a period that included the war years. When the university was hit during an air raid he is said to have acted with great calm and personal courage. His political tact made it possible to solve the wartime problems faced by the university as equitably as could be hoped for. He even found use for his mathematics when he devised a method to revise the ballistic tables of the artillery in a very short time.

In the years of his retirement he served as Chancellor of the University of Turku (Åbo). He was president of the International Union of Mathematicians 1959-1962. In a less official capacity he furthered the international relations between mathematicians by organizing support for an exchange of students between Finland and Switzerland as well as a series of conferences sponsored jointly by Finland and Romania.

Nevanlinna's personality was overwhelming, but at the same time warm, generous, and totally unselfish. In conversation he was able to create the impression that the person he was talking to was at the moment the only one who mattered. His charm worked equally well on men and women.

Rolf Nevanlinna married twice. His first wife, Mary Selin, was a cousin of his. 
They had three sons and a daughter, but they lost one of the sons to a war-related illness. The oldest son is an internationally known hematologist, Harry Nevanlinna. The younger, Aarne, is an architect. The daughter survived her father, but died soon thereafter, strangely in the same serious illness. The marriage to Mary ended in divorce. The second marriage was to Sinikka Kallio, an author, and lasted to his death. They had a daughter.

His last illness was a great burden, but he is said to have taken it with the same dignity that had characterized his whole life. To the last day he showed more concern for the problems of others than for his own. 